\title{
O Ministério Paulino e os Coríntios na economia da Nova Aliança: uma abordagem retórico-literária de 2 Cor 3,1-18
}

\author{
The Pauline Ministry and the Corinthians in the New \\ Covenant Economy: \\ An Rhetoric-Literary approach to 2Cor 3, 1-18
}

Jean Richard Lopes

\section{Resumo}

Este artigo propõe uma análise de 2Cor 3,1-18. A questão a ser enfrentada diz respeito ao ministério paulino e à sua recepção entre os coríntios. Nessa relação surge não somente a necessidade de defesa, da parte do apóstolo, do seu ministério, mas visa a orientar os coríntios a uma melhor compreensão da participação deles na economia da nova aliança. A abordagem exegética segue a análise retórico-literária. Com uma impostação pastoral, Paulo propõe uma argumentação estruturada e com uso de artifícios literários típicos da arte da oratória. Será desenvolvida uma análise particularizada, considerando cada micro-unidade do texto, separadamente e como parte da dispositio, ou seja, da organização interna da perícope: subpropositio-ratio (vv. 1.2-3), argumentativo I (vv. 4-6. 7-11), argumentatio II (vv. 12-17), peroratio (v. 18). Assim como a identificação da presença dos vários recursos retóricos (construções antitéticas, amplificatio, figuras de linguagem) usados pelo Apóstolo, na composição do texto e da pertinência para a sua compreensão. A conclusão trata do gênero retórico prevalente na unidade retórica, deixando clara a impostação e o objetivo de Paulo ao tratar do tema. As temáticas mais representativas do texto, de grande densidade teológica, são condensadas em três áreas inter-relacionadas: Ministério da Nova Aliança, Pneumatologia e Eclesiologia. 
Palavras-chave: Ministério. Nova Aliança. Pneumatologia. Eclesiologia.

\begin{abstract}
This article proposes an analysis of 2Cor 3,1-18. The question to be addressed concerns the Pauline's ministry and its reception among the Corinthians. In this respect not only the need arises for defense, of the apostle, of his ministry, but it aims to guide the Corinthians to a better understanding of their participation in the economy of the new covenant. The exegetical approach follows the rhetoric-literary analysis. With a pastoral approach, Paul proposes a structured argumentation and uses literary devices, typical of the art of oratory. A particularized analysis, considering each micro-unit text - separately and as part of whole dispositio - will be developed, focus on the internal organization of the pericope: subpropositio-ratio (vv. 1. 2-3), argumentatio I (vv. 4-6. 7-11), argumentatio II (vv. 12-17), peroratio (v. 18). And also the identification of the presence of several rhetorical devices (antithetical buildings, amplificatio, figures of speech) used by the Apostle in the text composition, that are relevant to understand the rhetorical unity. The conclusion will establish the prevalent gender rhetorical in the pericope, making clear the perspective and Paul's goal to address the issue. The most representative themes of the text, of great theological density, are condensed into three interrelated areas: Ministry of the New Covenant, Pneumatology and ecclesiology.
\end{abstract}

Keywords: Ministry. New Covenant. Pneumatology. Ecclesiology.

\title{
Introdução
}

A perícope de 2 Cor 3 tem sido motivo de debate há vários anos. É, sem dúvida, uma unidade literária densa, na qual se focam, sobretudo, os temas do ministério e do Espírito, mas também, numa leitura atenta, percebem-se questões eclesiológicas.

O presente artigo propõe uma interpretação da perícope a partir da abordagem retórica. Tal abordagem pressupõe que nas cartas paulinas encontram-se estratégias literárias típicas da retórica, sendo então dotadas de um dinamismo persuasivo ou dissuasivo dos seus destinatários. 
Antes de iniciar, cabe uma ressalva metodológica. O rhetorical criticism, nome dado ao conjunto de abordagens inspiradas na retórica, sofreu algumas críticas pertinentes, mais recentemente. A crítica retórica partia, muitas vezes, da determinação do gênero retórico, o que se revelou condicionante na exegese, porque, ao estabelecer o gênero corria-se o risco de enquadrar o texto num esquema fechado ${ }^{1}$. Paulo, com sua genialidade, é muito mais livre do que, às vezes, se afirma.

J.-N Aletti, atento a esse perigo, propôs um caminho que parte da dispositio $^{2}$ da carta - com a determinação da compositio - e da individuação das propositiones $^{3}$. Somente ao final dessa análise, é possível identificar o gênero retórico com mais segurança ${ }^{4}$, evitando condicionamentos prévios. Nessa linha, A. Pitta fala de análise retorico-literária, uma vez que da estrutura literária se passa à dispositio. Nesse artigo, se apresentará, após a delimitação da perícope, a sua composição retórico-literária, e, em seguida, uma exegese particularizada das partes (dispositio).

${ }^{1}$ Cf. PITTA, A. Disposizione e messaggio della Lettera ai Galati. Analise retorico-letteraria. AnBib 131. Roma: Ed. Pontificio Istituto Biblico, 1992, p. 36; ALETTI, J.-N. "La dispositio rhétorique". New Testament Studies 38 (1992), p. 390.

${ }^{2}$ A disposição (dispositio) do discurso é constituída pelo seu aspecto interno (divisão das partes), chamado composição (compositio). A dispositio é condicionada pela inventio, ou seja, pela escolha do material a ser empregado (provas argumentativas, exemplos) e do uso de elementos artísticos (figuras de linguagem e de pensamento), decididas pelo orador/autor. Cf. LAUSBERG, H. Handbuch der Literarischen Rhetorik. Eine Gurndlegung der Literaturwissenschaft. Stuttgart: Franz Steiner Verlag, 1990, pp. 443-446.

${ }^{3}$ A propositio evidência a temática central da argumentação. Cf. ARISTOTELIS. Rhétorique. Paris: CUF, 1980, III.13.1414a,1414b. Todavia, deve-se considerar que ela não se limita a apresentar uma temática importante, mas desencadeia uma argumentação que gera uma macro ou microunidade. A propositio principal pode se subdividir em outras (sub)propositiones (de macro e microunidade), tratando vários aspectos e aprofundamentos nas unidades que compõem o texto. Cf. ALETTI, J.-N. "La dispositio rhétorique", pp. 398-399; ALETTI, J.-N. "La rhétorique paulinienne: Construction et communication d'une pensée". In: DETTWILER, A.; KAESTLI, J.-D.; MARGUERAT, D. Paul. Une théologie en construction. MBib 51. Fribourg - Paris - Montréal: Labor et Fides, 2004, pp. 49.60-62. Deve-se evitar de absolutizar a importância das partes gerais da argumentação, pois nem mesmo a propositio é sempre identificável. PITTA, A. 'Così 'inesperto nell'arte retorica?' (cf. 2Cor 11,6). Retorica e messaggio paolino”. In: FABRIS, R. La parola di Dio cresceva (At.12,24): Fs. C.M. Martini. Rivista Biblica Supplementi 33. Bologna: EDB, 1998, pp. 411-435.420.

${ }^{4}$ Cf. ALETTI, J.-N. "La dispositio rhétorique", pp. 385-401; PITTA, A. "Così "inesperto nell'arte retorica?' (cf. 2Cor 11,6)”, pp. 422-423. Nesse artigo, o gênero retórico será apresentado na conclusão. 


\section{Delimitação}

A delimitação de 2 Cor 3,1-18 é discutida. Com algumas variações, muitos outros estudos tendem a identificar seus limites entre 2Cor 2,14 e 4,65. Na delimitação proposta, aqui, seguiu-se basicamente dois critérios: 1. frequência do vocabulário usado e de elementos de conexão sintática; 2 . mudanças ou saltos argumentativos.

Os critérios lexicográficos evidenciam a conexão interna da perícope e, assim, oferecem indícios para a determinação da mesma. Os termos de ministério (diakonía), ministro (diákonos) e ministrar/servir (diakonéō) estão presentes em toda a carta (13x), agrupados sobretudo em 2 Cor 8 e 9 (9x) e em 2 Cor 3 (6x). A ampla presença dos vocábulos na carta confirma a relevância do tema. Todavia, é importante considerar que Paulo desenvolve uma argumentação segmentada, por meio de unidades lógicas, relativamente curtas, autônomas e, ao mesmo tempo, em relação ${ }^{6}$. Isso é evidente em 2 Cor 3, onde se dá uma concentração desses termos numa argumentação elaborada na perspectiva da antítese ${ }^{7}$ entre dois âmbitos e modelos, da antiga e nova aliança.

Os vocábulos glória (dóxa) e glorificar (doxázō) também são concentrados em 2 Cor $3(11 \mathrm{x})$, aparecendo mais 5 vezes no restante da carta. Nesse capítulo, os termos são usados em construções marcadas pela antítese entre os

\footnotetext{
${ }^{5}$ Cf. LAMBRECHT, J. "Structure and Line of Thought in 2Cor 2,14-4,6". Biblica 64 (1983), pp. 344-380; SEGALLA, G. "Struttura letteraria e unità della 2 Corinzi”. Teologia 13 (1988), pp. 195-196; WRIGHT, N. T. The Climax of the Covenant. London - New York: T\&T Clark, 1991, p. 175; THRALL, M. E. A Critical and Exegetical Commentary on The Second Epistle to the Corinthians. I. ICC. London - New York: T\&T Clark, 1994, pp. 188-319; KUSCHNERUS, B. Die Gemeinde als Brief Christi: Die kommunikative Funktion der Metapher bei Paulus von 2Kor 2-5. FRLANT 197. Göttingen: Vadnehoeck \& Ruprecht, 2002, pp. 101-234; HARRIS, M. J. The Second Epistle to the Corinthians: A Commentary on the Greek Text. Grand Rapids: Eerdmans, 2005, pp. 241-337; MANZI, F. Seconda Lettera ai Corinzi. Paoline: Milano, 2002, pp. 35.118-187. Para algumas propostas a partir da abordagem retórica, cf.: AMADOR, J. D. H. "The Unity of 2 Corinthians. A Test Case for a Re-discovered and Re-invented Rhetoric". Neotestamentica 33 (1999), pp. 411-432; STEGMAN, T. The Character of Jesus. The Linchpin to Paul's Argument in 2 Corinthians. AnBib 158. Roma: Ed. Pontificio Istituto Biblico, 2005,pp. 233-247; PITTA, A. La seconda lettera ai Corinzi. Roma: Borla, 2006, pp. 51.144-211.

${ }^{6}$ Cf. ALETTI, J.-N. "La dispositio rhétorique”, pp.392.399-400; ALETTI, J.-N. La lettera ai Romani, p. 15.

${ }^{7}$ A antítese é um artificio retórico presente em toda 2 Cor, mas há uma aplicação significativa em 2Cor 3,1-18. O estudo do conjunto argumentativo da perícope e do seu desenvolvimento permitirá entender melhor a separação entre 2 Cor 3 e 4 .
} 
dois modelos de ministério: 1. o antigo, mosaico, com sentido de passageiro; 2. a realidade da nova aliança, positiva e atual. Diferente de 2 Cor 4,6, citação mais próxima, onde glória é utilizada em relação a Cristo, unicamente em sentido positivo.

O par véu (kálymma) e desvelar (anakalýptō) é empregado em 2 Cor 3 como uma importante metáfora que retoma uma experiência das origens de Israel como povo. Colocada em contraposição com a situação atual dos coríntios, esses termos reforçam a contraposição já acenada, sendo que no uso mais próximo de desvelar, em 2 Cor 4,3 (2x), também aqui, é relacionado diretamente a Cristo.

Espírito (pneûma) é outro vocábulo presente em toda a carta (14x), nem sempre com o mesmo significado. É distribuído em todas as partes da perícope (v. 3.6[2x].8.17[2x].18), como expressão da pessoa divina, em relação com Deus e o Senhor. Com essa conotação, além de 2Cor 3, é empregado somente em 2 Cor 5,$5 ; 13,13$.

Outro agrupamento terminológico expressivo designa o capaz/digno ( $h \mathrm{i}$ kanós), capacidade (hikanótēs) e capacitar (hikanóō). Com os versículos imediatamente antecedentes, o único ponto de contato lexicográfico entre 2Cor 2 e 3 é capaz/digno (hikanós), de 2 Cor 2,16c. Se a repetição do vocabulário indicaria um ponto direto de conexão (delimitação), do ponto de vista retórico, consideram-se também aspectos deduzidos do enunciado, com muitas nuances, que mostram a complexidade da situação retórica e a distinção das unidades. Por isso, enquanto 2 Cor 2,16c apresenta uma pergunta retórica geral, 2Cor 3, passa a uma argumentação mais específica.

Outros termos, de uso exclusivo de 2Cor 3 também favorecem o desenvolvimento da arguição de 2 Cor 3 , colocando em relação os termos apresentados antes, as partes da dispositio e destacando os âmbitos de comparação: aliança (diathékēe [v. 6.14]), Moisés (Mō̈̈sés [v. 7.13.15]), rosto (prósōpon [v. $7\{2 \mathrm{x}\} .13 .18]$ ), passar/cancelar (katargéó $[7,11,13,14])$. Outros termos não são exclusivos, mas muito significativos, seja na conexão com as questões da problemática geral da carta, a compreensão do ministério paulino, como também no desencadear da arguição da perícope específica: recomendar (synistēmi [2Cor 3,1;4,2; 5,12;6,4; 7,11;10,12.18]), com seu objeto, a carta (epistolé).

Portanto, a repetição de alguns termos, mesmo que no contexto imediatamente próximo, mais que antecipar o campo da delimitação para 2Cor, 2,14 ou estender até 2 Cor 4,6, mostram o quanto 2 Cor 3, como um tijolo num grande muro, está em sintonia com o tema central da carta (propositio generalis, 
2Cor 1,12-14) e com a sua variação mais imediata (propositio [2Cor 2,14-17] da macro-unidade de 2,14-7,16).

É importante também avaliar algumas mudanças e/ou possíveis saltos argumentativos, confrontados com marcos sintáticos, considerando o desenvolvimento retórico mais próximo. A passagem entre 2Cor 2,15-17 e 2 Cor 3 não apresenta algum marco sintático (conjunção coordenativa ou subordinativa, partículas) de conexão. Todavia, o fator mais relevante é que 2 Cor 3 se abre com duas perguntas retóricas, fortemente pessoais, com o emprego da primeira pessoa plural, a diferença de 2 Cor 2,16c, com uma pergunta retórica na terceira pessoa plural. O conteúdo da pergunta também difere: 2Cor 2,16c, sobre a idoneidade/capacidade; 2 Cor 3,1ab, sobre recomendação. As perguntas de 2 Cor 3,1ab são uma variação daquela de 2 Cor 2,16c e desencadeiam uma argumentação própria, dentro da resposta progressiva por unidades.

Um ponto mais exigente encontra-se na passagem entre 2 Cor 3 e 4, com a expressão "por isso" (diá toûto) (2Cor 4,1$)^{8}$. Tal expressão é referida ao que foi dito antes ou ao que segue? Existem, de fato, pontos de contatos lexicográficos de 2Cor 4,1-6 com o que antecede, sobretudo com 2Cor 3,7-18. No entanto, acredita-se que seja melhor interpretar diá toûto como referente ao que segue, porque Paulo muda a sua perspectiva9. Em 2Cor 4,1-6, ele apresenta a base da diaconia na misericórdia de Deus e deixa de empregar a perspectiva antitética de 2Cor 3. Chama a atenção também o emprego de "não desanimar"

\footnotetext{
${ }^{8}$ A. Plummer, embora entenda 2Cor 4,1-6 conectado com capítulo anterior, admite que a passagem entre 2Cor 3 e 4 é "unintelligently made". Cf. PLUMMER, A. Critical and Exegetical Commentary on the Second Epistle to the Corinthians. Edinburgh: T\&T Clark, 1915, p. 109. ${ }_{9}^{9}$ Assim também, BRUCE, F. F. 1 and 2 Corinthians. NCB. Grand Rapids - London: Eerdmans - Marshall, Morgan \& Scott, 1971, pp. 194-206; BARRET, C. K. A Commentary on the Second Epistle to the Corinthians. New York - London: Adam \& Charles Black, 1973, p. 127; MARTIN, R. P. 2 Corinthians. WBC 40. Waco: Word, 1986, p. 76; CARREZ, M. La deuxième épître de Saint Paul aux Corinthiens. CNT VIII. Genève: Labor et Fides, 1986, pp. 17.106; Witherington, B. Conflict \& Community in Corinth. A Socio-rhetorical Commentary on 1 and 2 Corinthians. Grand Rapids: Eerdmans, 1995, pp. 384-389; LONG, F. J. Ancient Rhetoric and Paul's Apology. The Compositional Unity of 2 Corinthians. Cambridge: Cambridge Universtiy Press, 2004, pp. 167-168. Embora com uma delimitação muito similar à de J. Lambrecht, M. E. Thrall também interpreta a locução preposicional como referida ao que segue. Cf. II Corinthians, I, 298. Mas ambígua é a posição de M. D. Given, segundo quem diá toûto pode ser entendido como elemento que anuncia a conclusão de um argumento. Por isso, indica olhar para a frente (ele define 2Cor 4,1-4 como "crab words"), mas ao mesmo tempo, há, porque conclusão, uma conexão direta com o que antecede. Cf. GIVEN, M. D. Paul's True Rhetoric. Ambiguity, Cunning, and Deception in Greece and Rome, Harrisburg: Trinity, 2001, p. 118.
} 
(ouk enkakoûmen ${ }^{10}$ [2Cor 4,1]), repetido depois em 2 Cor 4,16, como uma inclusão.

Se em 2Cor 3, Paulo discorre sobre o ministério operado por Cristo sob o raio de ação do Espírito, em 2Cor 4,1ss, decisivamente, ele passa a refletir sobre o ministério na perspectiva da ótica humana que se vive em meio a dificuldades, das mais variadas possíveis ( 2 Cor $4,7 \mathrm{ss}$ ), a começar pela possibilidade de desanimar-se. Por isso, nesse artigo, 2Cor 3,1-18 é considerada uma unidade literária bem construída, com uma arguição lógica e significativa.

\section{Composição da perícope (2Cor $3,1-18)$}

A disposição da perícope é bem singular e apresenta uma articulação retórica intrincada, com a reversio (inversão) da propositio / ratio e probatio, como se verá em seguida. Do ponto de vista estilístico, prevalecem elementos antitéticos e de amplificatio (amplificação) ${ }^{11}$.

A composição, aqui proposta, estrutura a perícope em quatro partes:

$\begin{array}{ll}\text { Subpropositio } & \text { v. } 1 \\ \text { Ratio } & \text { vv. } 2-3 \\ \text { I } \text { Argumentatio } & \text { vv. } 4-11 \\ 1^{\circ} \text { parte } & \text { vv. } 4-6 \\ 2^{\circ} \text { parte } & \text { vv. } 7-11 \\ \text { II } \text { Argumentatio } & \text { vv. } 12-17 \\ \text { Peroratio } & \text { v. } 18\end{array}$

A microunidade ${ }^{12}$ inicial (vv. 1-3) consta de duas partes muito bem conexas entre elas. A primeira (v. 1), a subpropositio, desencadeia a argumen-

${ }^{10}$ Cf. BAUER, W.; ARNDT, W. F.; GINGRICH, F. W.; DANKER, F.W. A Greek-English Lexicon of the New Testament. Chicago - London: University of Chicago Press, $1979^{2}$, p. 215 (nas notas a seguir, será citado como $B A G D$ ).

11 Um conjunto de procedimentos, com efeito retórico, para dar sempre maior amplidão e intensidade aos elementos empregados na argumentação, assim como nas expressões usadas. Cf. MORTARA GARAVELLI, B. Manuale di retórica. Milano: Bompiani, 2002, p. 109;

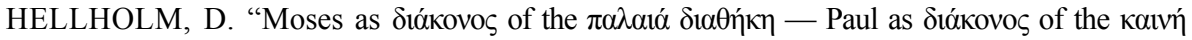
$\delta \iota 0 \theta \dot{\kappa} \eta$. Argumenta amplificationis in 2Cor 2,14-4,6". Zeitschrift für die Neutestamentlische Wissenschaft 99 (2008), pp. 246-289.

12 Microunidade corresponde às partes da perícope, enquanto o conjunto será denominado unidade retórica ou literária. 
tação da unidade literária, com duas perguntas retóricas. À primeira vista, as interrogações parecem sugerir que o destinatário entende enfrentar questões relacionadas com seu comportamento (v. 1a) e a necessária autenticação (v. 1b) do seu ministério. Se assim o fosse, o foco seria a questão da credibilidade do seu serviço.

$\mathrm{Na}$ lógica do texto, era de se esperar que os vv. 2-3 respondessem às interrogações do v. 1, mesmo sendo elas perguntas retóricas. Porém, algumas particularidades mostram que a intenção de Paulo é outra. $\mathrm{O}$ verbo recomendar e o adjetivo recomendação (v. 1a.b) não se repetem na perícope. Retoma-se, em vez, o termo carta (epistolé), usado num sentido diferente ao de antes. De um documento material passa-se a uma acepção metafórica, atribuída aos coríntios.

A mudança de acepção no uso de "cartas" é significativa e serve como um indício retórico do foco do discurso. Se o problema de fundo é o forte desmerecimento do ministério do Apóstolo, devido à ausência das cartas que atestassem a autenticidade do mesmo (v. 1a), o foco se volta para os membros da comunidade (v. 1b). Do confronto com os adversários, a atenção passa, rapidamente, à relação do remetente com os destinatários.

Consciente da centralidade do Evangelho, Paulo mostra imediatamente que aquilo - melhor, quem - que constitui os coríntios uma carta capaz de atestar algo (v. 2c) é Cristo e a ação do Espírito (v. 3). Nessa lógica, ele insere o tema do ministério com o verbo ministrar (diakonéo) e a antítese entre dois modelos de vivência crente, simbolizados pelas tábuas de pedra e por aquelas de coração de carne.

Os vv. 2-3 direcionam a atenção do leitor para os versículos seguintes, com mais elementos para a reflexão, culminando no v. 18. Nesse sentindo, os vv. 2-3 apresentam a ratio, ou seja, um artifício retórico cuja função não é de responder de modo imediato ou exclusivo às questões do v. 1ab, mas de alargar a problemática da subpropositio, identificando melhor a questão debatida na argumentatio (argumentação), com as probationes ${ }^{13}$ - as probationes podem oferecer ulteriores justificativas da ratio, dando precisão. ${ }^{14}$

Para entender melhor como a microunidade inicial determina a argumentação da unidade retórica, é necessário observar a sua composição interna. Os vv. 1ab e 2-3 desempenham uma função literária, representada na composição

${ }^{13}$ Cf. LAUSBERG, H. Elementi di retorica. Bolonha: Il Mulino, 1969, pp. 43.370.

${ }^{14}$ Cf. ALETTI, J.-N. La Lettera ai Romani e la giustizia di Dio. Roma: Borla, 1997, p. 30. 
ABB' A', que, relativa ao sentido retórico do enunciado, colocam em relação remetente e destinatário, fazendo-os participantes diretos da argumentação e não somente emissor e receptor:
A (v. 1a) - Alude ao comportamento do remetente
B (v. 1b) - Os destinatários são envolvidos na questão
B' (v. 2) - Salto metafórico: os destinatários são a carta
A' (v. 3) - Os coríntios são definidos carta de Cristo, escrita com o Espírito do Deus vivente.
Ministrada por ele

O ponto A está em correspondência com A'. Em ambos se encontra algo referido a Paulo. O primeiro é sobre a autenticidade do ministério do remetente e de seus colaboradores (nota-se o plural). Enquanto no A'é especificada melhor a questão do ministério, sempre submetido a Cristo.

A definição da comunidade como "carta de Cristo" sublinha a condição particular dos coríntios. E afasta o diálogo da controvérsia, por mais férrea que ela seja. Mesmo sendo um tema tão importante, ao falar de seu ministério com um particípio na voz passiva (diakonètheîsa), Paulo argumenta, como em toda a carta, segundo uma argumentação teológico-pastoral ${ }^{15}$.

$\mathrm{O}$ ponto $\mathrm{B}$, em vez, introduz as cartas de recomendação e envolve os coríntios ("para vós ou da vossa parte"). E no B' eles são apresentados como "nossa carta". Tal composição destaca a inter-relação existente entre o ministério do apóstolo e a condição da comunidade. $\mathrm{O}$ que conta na inteligência do ministério, conta também na compreensão que a comunidade tem de si mesma. E a condição que diz o que é a comunidade, carta de Cristo, explicita o sentido do ministério.

A subpropositio + ratio, portanto, têm uma composição bipartida, formada por uma pergunta e uma afirmação (AA', BB'). Algo similar, como espelho amplificante, acontece na argumentatio $^{16}$, dividida em dois momentos: vv. 4-11 e 12-17.

\footnotetext{
${ }^{15}$ Cf. ALETTI, J.-N. New Approaches for Interpreting the Letters of Saint Paul. Collected Essays. Rhetoric, Soteriology, Christology and Ecclesiology. SubBi 43. Roma: GBP, 2012, p. 34.

${ }^{16}$ A argumentatio (argumentação) constitui o coração de todo o discurso. Nela concentram-se as probationes, provas, previamente agrupadas, na inventio (preparação). Há provas técnicas, determinadas por testemunhos reais ou evidências materiais; e não técnicas, ou seja, inventadas; loci e outros. Cf. QUINTILIANO, M. F. L'istituzione oratoria. V. Torino: UTET, 1996, pp. 4-5.
} 
A argumentatio I (vv. 4-6.7-11), determinada por A.A' (vv. 1a.3), é dividida em duas partes. A primeira, vv. 4-6, descreve a capacitação e definição do ministério, como da nova aliança. Com essa última expressão percebe-se um elemento de ruptura que evidencia uma característica particular, condição na qual estão inseridos aqueles que seguem a Cristo e na qual o serviço é exercido. A nova aliança pressupõe uma antiga, com a qual está em relação antitética. $\mathrm{O}$ aspecto antagônico continua nos vv. 7-11, onde o serviço é apresentado através do confronto entre dois tipos de glória.

A conexão da argumentatio II (vv. 12-17) com a ratio não é identificável facilmente. Porém, ao considerar o sentido retórico do enunciado, B.B' (vv. 1b.2) acentuam a questão sobre a diferença entre judaísmo e cristianismo. A melhor compreensão do ministério depende também de uma melhor distinção de ambos os modelos religiosos e as respectivas conseqüências na comunidade.

A subpropositio, amplificada pela ratio, impostou a argumentação segundo uma perspectiva teológico-pastoral. Na peroratio (v. 18), Paulo trata da ação do Espírito que transforma o crente à imagem do Senhor, condição que caracteriza o exercício do ministério e a constituição da comunidade, no âmbito da nova aliança.

\section{Análise particularizada da perícope}

A seguir, será feita uma análise particularizada (dispositio), considerando elementos de sintaxe e semântica, seguindo a composição proposta, para evidenciar a dinâmica argumentativa da mesma.

\subsection{Subpropositio + ratio: vv. 1.2-3}

As duas perguntas retóricas (v. 1ab) esperam uma resposta negativa, determinadas pelo pronome interrogativo $m \bar{e}$. Elas introduzem o tema da recomendação. O verbo (synístēmi) e o substantivo (systatikós) da recomendação ${ }^{17}$ aludem a uma prática comum, inclusive entre as comunidades cristãs, do uso

\footnotetext{
${ }^{17}$ Como transitivo, o verbo synistèmi significa mostrar, evidenciar, manifestar, demonstrar

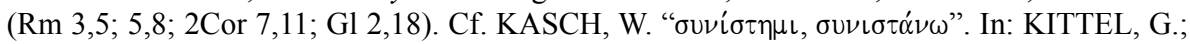
FRIEDRICH, G. (Ed.) Theologisches Wörterbuch zum Neuen Testament. VII. Stuttgart: W. Kohlhammer Verlag, 1964, pp. 895-896 (nas notas a seguir, esse dicinário será indicado pela sigla $T h W N T$, mais o número do volume citado).
} 
de um documento que ateste a autenticidade de quem a carrega. No contexto, Paulo é acusado ${ }^{18}$ de não ter algum documento que comprovasse a validade de seu ministério.

No v. 1a, se parte da recomendação como uma exigência e se passa à sua forma material (v. 1b). Isso corresponde a uma intenção retórica que desemboca nos vv. 2-3, com o uso metafórico de "carta" aplicado aos destinatários. Eles não são meros ouvintes ou expectadores, mas chamados a tomar posição a partir da condição nova na qual foram inseridos, no âmbito que o ministério de Paulo é atuado. Assim, o Apóstolo direciona a atenção para questões além de uma apologia pessoal.

Astutamente e com grande impacto emotivo ${ }^{19}$, no v. 2 , o remetente promove uma conexão entre a temática da autenticidade do ministério e a sua relação com comunidade. Ele não ignora as acusações sofridas, mas afirma ter também ele uma documentação que comprove a autenticidade do seu serviço: a comunidade de Corinto, seus verdadeiros interlocutores ${ }^{20}$.

A associação dos coríntios à carta é especificada por três frases participiais referidas à epistolé. O primeiro, engegramménē (escrever - inscrever ${ }^{21}$ ), destaca a qualidade perfectiva, que, devido à idéia de algo que perdura, reforça a certeza de que a relação do apóstolo com os coríntios vai muito além de

\footnotetext{
${ }^{18}$ Os acusadores são apresentados com uma fórmula genérica, "como alguns", que provoca o espírito engenhoso dos exegetas, na busca da sua identidade. Cf. THRALL, M. E. A Critical and Exegetical Commentary on The Second Epistle to the Corinthians, p. 29; PITTA, A. La seconda lettera ai Corinzi, pp. 51.147. A busca da identificação dos opositores esbarra na dificuldade de uma conclusão mais segura, devido à apresentação vaga feita por Paulo - o Apóstolo, obviamente, não tem nenhum interesse de fazer propaganda dos seus opositores, mas de responder a questões pertinentes à relação com os destinatários -, e na ausência de outro material que permita estabelecer a identidade desses opositores. Cf. BRODEUR, S. N. Il cuore di Paolo è il cuore di Cristo. Studio introduttivo esegetico-teologico delle lettere paoline. I. Theologia, 2. Roma: G\&B Press, 2010, pp. 74-75; SCHÜTZ, J. H. Paul and the Anatomy of Apostolic Authority. New Introduction by Wayne A. Meeks. Louisville - Westminster: John Knox Press, 2007, p. 3.

${ }^{19}$ A eficácia da oratória depende também da concatenação dos três âmbitos fundamentais da comunicação: o orador (ethos) e sua credibilidade, o discurso (logos) e seu conteúdo, os destinatários (pathos) e a recepção do discurso que inclui o fator emocional. Na linguística moderna, se fala da interlocução entre autor, texto e leitor. Cf. PITTA, A. "Così 'inesperto nell'arte retorica'?", p. 422.

${ }^{20} \mathrm{O}$ uso de um vocábulo com significados diferentes é típico da figura de linguagem conhecida como reflexio. Cf. LAUSBERG, H. Elementi di retorica, p. 292.

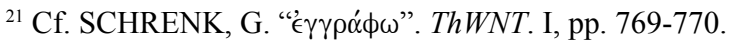


um aspecto convencional, confirmado pelo complemento preposicional: nos nossos corações ${ }^{22}$.

Os particípios, ginōskoméne (conhecer) e anaginōskoménē (ler), reforçam a metáfora num sentido mais aberto, publico ${ }^{23}$. Paulo mostra não se interessar por uma carta de autenticação diante da comunidade. Porém, ele espera que os coríntios, assumindo um comportamento realmente comunitário ${ }^{24}$ e menos conflitivo, tornem-se, para aqueles que entrarem em contato com a comunidade, uma ocasião (conhecer) para adentrar (ler) naquilo que os configurou uma Igreja de Deus (2Cor 1,1), conforme o evangelho recebido.

Com um raciocínio hiperbólico, o público para o qual a carta de recomendação é apresentada é bastante amplo: "por todos os homens". Algo com um efeito comparativo de grande força, pois os adversários paulinos não podem se permitir algo igual.

Num movimento ascendente, a metáfora dá um salto qualitativo e significativo $^{25}$. Invocando a idéia de uma revelação (faneroúmevoi + hót ${ }^{26}$ ), os coríntios são definidos como uma carta de Cristo (v. 3a), direcionando a inteira comunidade para sua origem, no encontro com o evangelho.

Diante da autoria de Cristo, Paulo introduz o tema do ministério (2Cor 3,6.8.19.20; 6,4; 11,15[2x].23). O particípio passivo (diakonētheísa) mostra a convicção da importância da sua missão ${ }^{27}$. Ele sabe bem que seu esforço na

${ }^{22} \mathrm{Na} 2 \mathrm{Cor}$, o substantivo kardía (coração) segue a linha presente no AT e na LXX, entendido como lugar da interioridade e da vida psíquica e espiritual (2Cor 1,22; 4,6; 1Cor 2,9; 4,5). Cf. BEHM, J. “к $\alpha \rho \delta i ́ \alpha ” . ~ T h W N T$. IX, pp. 611-616.

${ }^{23} \mathrm{O}$ verbo anaginốskō significa ler em voz alta e dirigido a um público. Cf. BULTMANN, R.

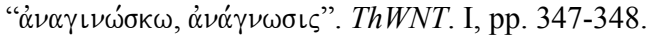

${ }^{24}$ Em 2Cor 8,7-8, Paulo apela ao exceder dos coríntios na fé, na palavra, doutrina e zelo, assim como na caridade que ele os ensinou para incentivar a coleta a favor de Jerusalém.

25 Paulo aplica a correctio (correção), um tipo de amplificação qualificada como incrementum: um crescimento gradual do conceito ou ideia descritas. Cf. LAUSBERg, H. Handbuch, p. 784. No caso, a gradualidade que amplia o sentido é aplicada ao vocábulo carta. De um documento material, texto escrito, Paulo passa para o uso metafórico aplicado à comunidade, uma realidade não literária, mas sim existencial e relacional, com a qual ele se esforça para renovar os laços, sempre na perspectiva de Cristo, como se vê claramente no que segue.

${ }^{26}$ Cf. $B A G D$, p. $853.2 \mathrm{~b}$.

${ }^{27} \mathrm{O}$ verbo servir/ministrar e os substantivos diácono e diaconia são muito presentes na 2 Cor e na perícope aqui estudada. Do antigo significado de servir (servidor, serviço) à mesa, esses vocábulos adquirem na comunidade primitiva uma polissemia: um serviço à comunidade (At 1,17.25; 20,24; 21,19; Rm 11,13; 2Cor 4,1; 6,3; 11,8; Ef 4,11; 1Tm 1,12), vivido por meio da palavra proclamada, com o serviço oferecido (At $6,2.4$; 1 Pt 1,12; 4,10-11ss) e colaboração (At 19,22; Flm 13); uma função eclesial em conexão com o episcopado (F1 1,1; 1Tm 3,8.12; 4,6). 
fundação, como intermediário, deu visibilidade histórica ao Evangelho, levando os coríntios ao encontro com Cristo, o autor.

A característica da carta (metafórica) é explicitada pela antítese que evidencia que a sua superioridade é determinada por um substrato não material, mas sim pelo "Espírito do Deus vivente" (v. 3). A qualidade do substrato é reconhecida pelo genitivo "do Deus vivente". Na segunda antítese, se focaliza o "lugar" da inscrição do Espírito, ou seja, no coração. Certamente, o Apóstolo, ao falar de tábuas de pedra, pensava no $\mathrm{AT}^{28}$.

O paralelo das antíteses (v. 3) evidencia a fundação da comunidade por meio de uma ação divina, como aconteceu com Israel no Êxodo e que o Apóstolo define como obra do Espírito do Deus vivente. Alguns temas, aliança e diaconia, serão retomados na perícope e explicados num horizonte novo. A ratio, portanto, expande a subpropositio, indo além da apologia, porque, junto à credibilidade do ministério paulino, os coríntios precisam refletir a própria condição performativa.

\subsection{Argumentatio: vv. 4-6.7-11}

$\mathrm{Na}$ I argumentatio, passa-se à análise das probationes. Divida em duas partes, vv. 4-6 e 7-11, ela se abre com uma afirmação categórica determinada pela "confiança" (v. 4), em sequência com o que já fora afirmado (vv. 2-3). Tal confiança é embasada na ação de Cristo e na relação com Deus.

Um aprofundamento ulterior, nos vv. 5-6, retoma o tema da credibilidade do apostolado paulino. Ao usar o vocabulário da suficiência e capacitação (hikanoí, hikanótēs, hikanóó) $)^{29}$, Paulo deixa claro que ele não tem autoridade para pretender ou apropriar-se de um ministério, como o de apóstolo. Endereça, então, o entendimento de seus interlocutores para a origem divina do próprio ministério, enquanto é Deus aquele que o capacitou como diácono.

Paulo denomina e apresenta alguns personagens próximos a ele como diáconos ( $\mathrm{Rm} 16,8$; Ef

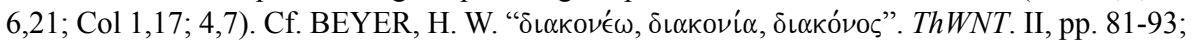
CLARKE, A. D. A Pauline Theology of Church Leadership. LNTS 362. London - New York: T\&T Clark, 2008, pp. 60-71.

${ }^{28}$ Cf. Ex 24,12; 31,18; 34,1; Dt 9,10.11. A imagem das tábuas de coração de carne encontra-se já no AT: Jr 38,31 [LXX] (31,31[-33] TM); Ez 11,19; 36,26; Pr 3,1; 7,3.

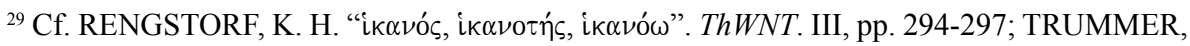

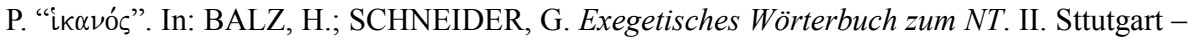
Berlin - Köln, $1992^{2}$, pp. 452-453 (nas notas a seguir, esse dicinário será indicado pela sigla $E W N T$, mais o número do volume citado). 
A função para a qual ele é habilitado, diácono/ministro, é especificada pela expressão "nova aliança". O adjetivo "nova" garante à "aliança" um valor positivo e distinto da "antiga aliança" (v. 14). No v. 6 a "nova aliança" também é explicada em associação ao Espírito contraposto a um elemento material, a letra. Do ponto de vista argumentativo, a contraposição explicita duas concepções diferentes do ministério, do seu exercício e consequente fruto. Ao invocar o Espírito, Paulo vai além da questão conceitual e direciona o leitor para uma realidade dinâmica e atuante na constituição da comunidade e do ministério, ambos em relação. A antítese adquire dramaticidade quando se observa a sua razão: a letra mata, o Espírito dá vida (Rm $2,[27] .29 ; 7,6)^{30}$.

Esforçando-se por ser mais objetivo, o texto continua com três períodos condicionais da realidade. Assim, o ministério da morte é contraposto ao do Espírito, o da condenação ao da justiça, o transitório ao permanente (vv. 7.8.9a.b.11a.b).

Chama a atenção o primeiro par de antípodas: morte e Espírito. Esperava-se que o autor usasse vida, contraposta à morte, e não Espírito. Todavia, no v. $6 \mathrm{c}$, o Espírito é apresentado como aquele que vivifica. Algo parecido encontra-se no v. 3b. O Espírito, então, é colocado em evidência, como a força vital contraposta a tudo aquilo que representa significativa e simbolicamente a antiga aliança que conduz à morte. E confirma o significado de vida, como objetivo do ministério novo.

O elemento antitético dos dois modelos é reforçado pela inserção da figura de Moisés (v. 7c). Associado a "letras e tábuas de pedra" (vv. 3.6.7), é uma clara referência ao tema da aliança anterior (v. 14b). O foco está no ministério, na modalidade, origem e exercício do mesmo, segundo a forma mosaica e paulina.

O grande legislador do AT é retomado segundo a prática retórica da syncrisis, isto é, a comparação de personagens e eventos, mostrando os pontos

\footnotetext{
${ }^{30}$ Nota-se uma argumentação do tipo a fortiori, a minore ad maius. A exegese rabínica denomina esse tipo de argumento qal waḥomer. Trata-se de uma argüição por analogia, na qual o fator que se usa para afirmar sobre uma parte do argumento, pode ser afirmado também da outra. As premissas das duas partes devem ser comuns. Cf. LAUSBERG, H. Handbuch, p. 395. Para outro exemplo similar, cf. Rm 5,9-10.11-12.15.17.24. Em termos de retórica clássica, esse artifício corresponde à comparatio, um dos quatro genera amplificationes (incrementum, comparatio, ratiocinatio, congeries). E consiste na apresentação de um exemplo que, gozando já de um alto reconhecimento, é progressivamente superado pela situação nova apresentada. $\mathrm{Cf}$. LAUSBERG, H. Handbuch, pp. 401-406 (mais especificamente, cf. p. 404).
} 
de contato, como também as diferenças ${ }^{31}$. O ponto de comparação é tomado de Ex 24,30. Acontecimento significativo na história de Israel, que integra a narração da constituição do povo de Deus. Paulo não segue ao pé da letra a descrição do $\mathrm{AT}^{32}$. A questão está na superioridade típica do ministério do Espírito, que produz novidade e diante do qual se reconhece uma característica de transitoriedade à primeira aliança.

Ao ministério de morte (v. 7a) é relacionado o ministério da condenação (v. 9a). Tal paralelo induz a pensar que o ministério sob a lei pode ser definido "de morte", porque a condenação é sinônima da experiência de morte, enquanto não participação na vida de Deus. Assim, o ministério que produz condenação, leva à morte. A superioridade, pela abundância (v. 10), não se refere ao simples somar em número ou extensão, mas sim pela densidade e intensidade, porque referido à disposição daqueles ou daquilo que cresce. $\mathrm{O}$ verbo abundar (perysseúō) é usado nos escritos paulinos como indicativo do crescimento de aspectos importantes e constitutivos da vida do cristão ${ }^{33}$ (1Cor 8,$8 ; 14,12$; 2 Cor 1,$5 ; 4,15 ; 8,2.7 ; 9,8.10 ;$ F1 1,9; 1Ts 3,12; 4,1.10).

Nos três períodos condicionais (vv. 7-8.9[10].11) a glória se apresenta de modo transversal. Ela é atribuída aos dois modelos. Esse fator descarta a possibilidade de esvaziar totalmente de importância o primeiro modelo e seu âmbito próprio, da antiga aliança. A glória na antiga aliança pode ser definida passageira (v. 7b), porque a sua manifestação concreta, o ministério, produz elementos de transitoriedade, caducidade (v. 11a), condenação e morte, simbolizados fortemente nas letras gravadas sob pedras (vv. 3b.c.7a). Em Cristo, ao contrário, a nova aliança adquire o caráter de permanente (v. 11b) e o serviço vivido nessa novidade, sob a autoridade do Espírito, gera justificação e

${ }^{31}$ Cf. ANDERSON JR, R. D. Glossary of Greek Rhetorical Terms: connected to methods of argumentation, figures and tropes from Anaximenes to Quintilian. Leuven: Peeters, 2000, pp. 110-111.

${ }^{32} \mathrm{Na}$ literatura judaica encontra-se uma atestação da crença de que os filhos de Israel não pudessem olhar para o rosto de Moisés. Cf. PHILON D'ALEXANDRIE. De Vita Mosis. II. Paris: Cerf, 1969, p. 70. Segundo A. Vanhoye, do temor de olhar não é difícil passar à idéia de não poder olhar. Cf. VANHOYE, A. "L'interprétation d'Ex 34 en 2Cor 3,7-14". In: LORENZI, L. de. (Org.) Paolo. Ministro del Nuovo Testamento. SMBen.Be 9. Roma: Benedictina Editrice, 1987, p. 161; PLUMMER, A. Critical and Exegetical Commentary on the Second Epistle to the Corinthians, p. 90; BULTMANN, R. Zweiter Korintherbrief. Göttingen: KEK Sonderband, 1976, p. 83; BELLEVILLE, L. L. "Tradition or Creation? Paul's Use of the Exodus 34 Tradition in 2 Corinthians 3,7-18". In: EVANS, C. A.; ANDERS, J. A. (Ed.). Paul and the Scriptures of Israel. JSTNSS 83. Shefield: Shefield Academic Press, 1993, pp. 165-185.

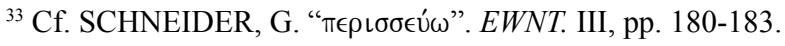


vida, significadas não por um material extrínseco, mas sim por uma realidade intrínseca (v. 3b), estabelecida no coração (v. 3c).

\subsection{Argumentatio: micro-unidade de 2Cor 3,12-17}

A II argumentatio, em sintonia com a subpropositio e a ratio (v. 1b.2[.3]), muda a perspectiva temática. $\mathrm{O}$ tema do ministério passa para um segundo plano, deixando espaço para a questão de como a comunidade é formada e sobre qual fundamento se sustenta. O ponto de comparação é ainda a aliança, explicitamente denominada "velha" (v. 10c). São introduzidos alguns dados novos que ajudam a evidenciar o foco da consciência da comunidade. Não tendo a intenção de fazer historiografia de Moisés e do estabelecimento da aliança, no AT, Paulo se sente livre para recuperar e, inclusive, alterar alguns dados da narração anterior, para levar seus interlocutores a refletirem sobre a própria condição, no horizonte da nova aliança.

O v. 12a introduz o termo esperança, que, como no v. 4, é um tema "gancho"; sustentado no que foi dito até então, funciona como um degrau de apoio para justificar a parresía ${ }^{34}$ (parrēsía [v. 12b]). Esse termo, na 2Cor, expressa o esforço de Paulo para renovar, no sentido de participação, compreensão e crescimento conjunto, a relação dele com os coríntios (2Cor 1,7; 10,15). No v. 12b, ela reaparece com sentido teológico, porque relacionada com algo garantido por Deus (v. 4-6.7-11). E, assim, alimenta a atitude do Apóstolo diante dos coríntios, comportando-se de modo franco.

A inteira asserção do v. 12, portanto, como uma dobradiça, é referida àquilo que foi desenvolvido até agora. $\mathrm{E}$, ao mesmo tempo, prepara os seus destinatários para o que vem depois. Paulo propõe com coragem a distinção entre o ministério mosaico, definido passageiro, e aquele que ele exerce, vivido abertamente. Contra o velho modelo e a favor do seu agir, os coríntios são convocados a reconhecer a franqueza do discurso do apóstolo que se fundamenta na confiança em Cristo, diante de Deus, como deixa entender o paralelo com 2 Cor 3,4.

O termo véu (v. 13) representa a ideia de obscurantismo e impedimento que afeta o olho (v. 13b), a mente e o coração dos israelitas (vv. 14a.15). Obviamente o texto do AT (Ex 34,33-35), ao qual Paulo se refere, não intencionava apresentar um Moisés que simplesmente esconde "algo" do povo,

\footnotetext{
${ }^{34}$ Seu significado indica um falar aberto e livre, com conotação de coragem, liberdade e

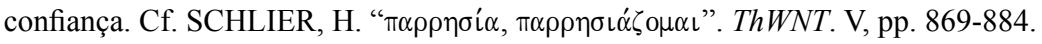


mas a Paulo serve a contraposição para confirmar a diferença dos modelos discutidos e introduzir com força os coríntios na reflexão

O véu os impedia de ver a glória transitória (v. 7d.13d). Ao falar de "fim" (v. 13d), certamente Paulo não pensa em algo somente do passado, mas na aliança antiga no seu continuar na história, até o seu momento. Por isso, a transitoriedade da glória evidencia a passagem de autoridade do ministério da antiga aliança para o novo, o seu ${ }^{35}$.

A consequência nos interlocutores é o endurecimento da mente. Esse termo denota a faculdade humana de pensar. Em três momentos, na Segunda Coríntios, o remetente alerta para o perigo de que a mente seja eclipsada e corrompida, como efeito da ação de uma força maléfica em oposição ao projeto de Deus (2Cor 2,11; 4,4; 11,3). E, em 2Cor 10,5, ela é apresentada como sinal de obediência a Deus, em Cristo (Fl 4,7). O valor iterativo do imperfeito "colocava" (v. 13) e da expressão "até hoje, o véu permanece" (v. 14b.15) apresenta o endurecimento como uma obstinada ligação com o velho.

$\mathrm{Na}$ linha da amplificatio por incrementum, a argumentação paulina cresce, corroborando sempre mais a diferença das duas modalidades, judaica e cristã, passando do ministério à vida comunitária.

$\mathrm{O}$ crescente drama da obstinação não deixa o leitor em suspenso quanto à possibilidade ou não de superação. O v. 16 indica o voltar-se ao Senhor como via de remoção do véu. O verbo voltar-se sugere direcionamento e, como tal, é imbuído também do sentido de conversão. Sendo um aoristo, poder-se-ia dizer que implica numa tomada de decisão pontual, que contemple Cristo como Salvador.

Paulo não apresenta de forma clara o sujeito do voltar-se. E, provavelmente, intencionava deixar vago, para que não somente os coríntios assumissem essa posição. De qualquer modo, no período condicional da eventualidade, indica que se o homem, quem quer que seja, decide voltar-se ao Senhor, pode estar certo de que o véu é removido.

Como uma nota explicativa do versículo anterior, o v. 17 relaciona três temas importantes: Senhor, Espírito e liberdade. Inicia com uma asseveração categórica, "o Senhor é o Espírito" (v. 17a), que é esclarecida no v. 17b. Ao relacionar diretamente Senhor e Espírito, seja com uma oração nominal (v. 17a) e uma forma constructa (v. 17b [genitivo]), o autor coloca o leitor diante de uma definição não fácil de ser entendida.

\footnotetext{
${ }^{35}$ Trata-se da questão do ministério e do conceito de comunidade, e não do cancelamento da aliança ou da lei. Cf. DAVIES, W. D. "Paul and the People of Israel". New Testament Studies 24 (1977-1978), pp. 11-12.
} 
Nos versículos anteriores encontram-se especificações das ações do Espírito e de Cristo. No v. 3 já era insinuada uma correlação enquanto o segundo era o autor da carta e o primeiro a tinta. Porém, nesse versículo, Paulo apresenta uma implicação importante da nova aliança: a integração da ação do Espírito e do Senhor, sem confundi-los. E a especificidade de cada ação se revela unida no estabelecimento da condição ou estado (v. 17ba) na qual o crente é inserido, ou seja, de liberdade.

O Espírito, portanto, promove a conexão com Cristo, estabelecendo a pertença (v. 3a), a economia na qual ela é vivida (v. 6) e a condição livre dos crentes (Rm 2,29; 7,6; 8,14-15; G1 5,18). Ao mesmo tempo em que a presença de Cristo se dá na ação do Espírito $(\mathrm{Rm} 8,2 ; \mathrm{Fl} 3,3)^{36}$.

\subsection{Peroratio}

De modo significativo, a peroratio, conclusão da unidade retórica, inicia-se com um sintagma nominal - "nós todos" (hēmeîs dè pántes) -, com uma função inclusiva. O adjetivo "todos" (pántes) desempenha uma função expansiva, sublinhando o fato de que o "nós" não diz respeito somente a Paulo e seus colaboradores, mas abrange todos aqueles que vivem segundo a nova aliança ${ }^{37}$. O sujeito inclusivo é definido a partir da reviravolta da condição apresentada no v. 14: com o rosto descoberto e contemplando a glória do Senhor.

A voz passiva do verbo principal, "somos transformados" (metamorphóo $)^{38}$, deixa imediatamente claro que o sujeito agente é o Espírito do Senhor, impedindo de atribuir a transformação a outra realidade, como à lei. Essa economia nova é dom do Senhor, por meio do Espírito. Diversamente dos Sinóticos (Mt 17,2; Mc 9,2), que usam o verbo no contexto da Transfiguração - com efeito visível, externo - Paulo fala de algo que acontece no interior do homem.

O termo eikốn, traduzido como imagem, não é limitado a uma representação figurada, com semelhança ${ }^{39}$. No NT, a imagem representada visivelmen-

\footnotetext{
${ }^{36}$ Embora com proporções diferentes, o uso de pneûma em 2Cor 3 situa o capítulo entre as perícopes pneumatológicas do espitolário paulino: Rm 8; 1Cor 12; Gl 5,13-25.

${ }^{37}$ Para outros exemplos do uso do sintagma com o mesmo sentido, abrangente, cf.: 1Cor 12,13; 2Cor 5,10; Ef 2,3; Jo 1,16.

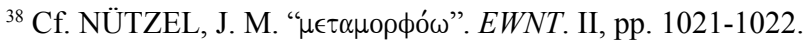

${ }^{39}$ Nesse caso seria usado homoíoma (Rm 1,23; 5,14; 6,5; 8,3; Fl 2,7; Ap 9,7). Cf. SCHNEIDER, J. “ó $\mu$ oí $\omega \mu \alpha$ ”. ThWNT. V, pp. 535-554.
} 
te é a mesma figura que manifesta a sua essência ${ }^{40}$ - a integridade do homem novo. O pronome atributivo, "mesma", deixa claro que se trata da imagem que leva em si a glória do Senhor, aquela que os crentes contemplam.

O sentido, portanto, que Paulo transmite, na peroratio ${ }^{41}$, é da participação da parte dos crentes na glória de Deus. Tal participação ocorre de forma dinâmica, num processo, como bem indica a locução preposicional "de glória em glória", entendida no sentido escatológico, que ocorre no interior do homem ${ }^{42}$.

\section{Conclusão}

A exegese desenvolvida, a partir da abordagem retórica, mostra a dinâmica crescente da argumentação presente no texto, até a sua peroratio. Agora, na conclusão, é importante retomar a questão do gênero retórico.

De fato, as duas perguntas retóricas da subpropositio do v. 1ab não escondem um fundo polêmico. Certamente alguns levantaram o problema da auto-recomendação do remetente. Todavia, não se limitando à disputa provocada pelos estrangeiros, Paulo vai além e propõe uma verdade geral que define os coríntios: "sois uma carta de Cristo, servida por nós" (v. 3) ${ }^{43}$. Se a comunidade é a maior recomendação que o Apóstolo tem, ela precisa ter consciência da sua condição. Afinal Paulo não chama os coríntios para a argumentação de modo utilitarista. A existência da comunidade, não obstante tudo, é uma prova da credibilidade do ministério. Mas para poder melhor viver a sua vocação (2Cor 1,26), é preciso adquirir, ou recuperar, a consciência da sua condição nova. Para isso o Apóstolo usa vários artifícios retóricos, numa argumentação teológica, a fim de dissuadir os coríntios das idéias contrárias ao evangelho

\footnotetext{
${ }^{40}$ Paulo usa esse vocábulo em três contextos: 1 . negativo, que trata da imagem do homem corruptível (Rm 1,23); 2. positivo, que fala da imagem divina que se manifesta no homem, no processo de tornar-se imagem do Filho ( $R m$ 8,29.30; Fl 3,21) e imagem de Deus (1Cor 11,7); 3. apresenta Cristo como imagem de Deus (2Cor 4,4; Col 1,15). Cf. KITTEL, G.; VON RAD,

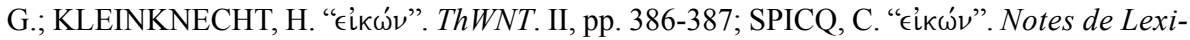
cographie Néo-Testamentaire: Supplément. Göttingen: Vandenhoeck \& Ruprecht, 1982, pp. 202-210.

${ }^{41}$ Cf. WRIGHT, N. T. The Climax of the Covenant. London - New York: T\&T Clark, 1991, p. 185.

${ }^{42}$ Cf. PLUMMER, A. Critical and Exegetical Commentary on the Second Epistle to the Corinthians, p. 107.

${ }^{43}$ Cf. CHEVALLIER, M.-A. Esprit de Die, paroles d'hommes. Le rôle de l'esprit dans les ministères de la parole selon l'apôtre Paul. Neuchatel: Delachaux and Niestlé, 1966, p. 69.
} 
da fundação (2Cor 10,4), porque desmerecer o ministério paulino equivale a depreciar o evangelho que ele apresentou à comunidade (2Cor 11,4.7). Se ele não é crível, seu evangelho também não o é. A solicitude pastoral de Paulo e a fidelidade ao evangelho, portanto, levaram-no a explicar o seu ministério numa argumentação mais ampla, que inclui os coríntios.

O ministério apostólico e o evangelho, assim como consciência da própria condição, adesão e coerência determinadas sempre pelo mesmo evangelho, são temáticas afins que se compreendem melhor quando lidas juntas - sabendo que o primeiro existe em função do segundo. Além do mais, Paulo se dirige a um cristianismo não abstrato, mas concretizado na comunidade.

Do ponto de vista da reflexão da fé, a presença dos opositores acaba por ser uma ocasião pastoral - que se lhe impõe - que estimula o Apóstolo a retomar questões eclesiológicas de base, ou seja, a centralidade Cristo. A questão em jogo é fundamental, porque relativa à mediação da salvação não mais atribuída à aliança antiga (Lei), mas a Cristo ${ }^{44}$, inaugurador da nova economia estabelecida por Deus.

Em 2Cor 3,1-18, Paulo evoca significativamente Moisés, o grande legislador do AT, colocando em evidência dois aspectos importantes. Primeiro, ele apresenta seu ministério na linha da história da salvação, dos grandes personagens do AT. Segundo, olhar para o evangelho significa ater-se à experiência performativa do povo de Deus, em Cristo, pelo Espírito, como uma novidade que ultrapassa os limites tradicionais do judaísmo ${ }^{45}$.

Após a análise da composição da micro-unidade, tendo em vista o dinamismo argumentativo explicitado pela composição, observa-se que o gênero retórico de 2 Cor 3,1-18 é o deliberativo ${ }^{46}$. Muitos afirmam ser o forense, apologético e de defesa ${ }^{47}$.

\footnotetext{
${ }^{44}$ A afirmação da Lei, como principio normativo e mediador de salvação, desmerece a redenção ocorrida em Cristo, o único mediador de salvação. Cf. PENNA, R. L'apostolo Paolo. Studi di esegesi e teologia. Cisinello Balsamo: Paoline, 1991, p. 452.

${ }^{45}$ Cf. RICHARD, E. "Polemics, Old Testament, and Theology. A Study of II Cor III,1-IV,6". Revue Biblique 88 (1981), p. 345.

${ }^{46}$ Esse gênero, como o jurídico, pretende mudar a situação vigente, levando os ouvintes a posicionar-se sobre algo que influenciará a vida doe todo o público. Cf. LAUSBERG, H. Elementi di retorica, p. 20.

${ }^{47} \mathrm{Na}$ história da exegese da $2 \mathrm{Cor}$, deu-se muita ênfase à auto-compreensão que Paulo tem do seu apostolado e sobre o problema dos adversários. Mas os destinatários da carta, os verdadeiros interlocutores do Apóstolo, são os coríntios e não seus adversários, como bem mostra 2 Cor 3,1-3; 5,11-13; 6,11-13; 7,2-4; 11; 12-14[15]; 12,19-21; 13,1-10. Cf. MURPHY-O'CONNOR, J. Paul the Letter-Writer. Collegeville: Litrugical Press, 1995, p. 70; BIERINGER, R. “Plädoyer
} 
A intenção de Paulo, portanto, não seria a de defender apologeticamente seu ministério, embora tivesse consciência de que os ataques sofridos influenciavam a comunidade, na sua experiência de fé e auto-consciência no mistério de Cristo. Por isso, ao explicar a origem e autenticidade do seu ministério, ele não condiciona, ou limita, a sua argumentação a uma defesa exclusiva de si, mas, sempre com solicitude e convicção pastoral, descreve o ministério em relação à comunidade no âmbito da nova aliança, ou seja, da condição nova inaugurada em Cristo e efetivada no Espírito Santo, deixando claro que o maior perigo, portanto, é o afastamento do verdadeiro evangelho.

A peroratio $(2$ Cor 3,18$)$ é teológica e colocada como fundamentação da consciência dos coríntios. Dentro do gênero deliberativo, tem a intenção pragmática, de um lado, de dissuadir os coríntios a não se deixarem levar pelas idéias estranhas ao evangelho e, do outro, estimulá-los a uma adesão de fé mais consciente.

\section{Referências bibliográficas}

ALETTI, J.-N. "La dispositio rhétorique". New Testament Studies 38 (1992), pp. $385-401$.

ALETTI, J.-N. La Lettera ai Romani e la giustizia di Dio. Roma: Borla, 1997.

ALETTI, J.-N. "La rhétorique paulinienne. Construction et communication d'une pensée". In: DETTWILER, A.; KAESTLI, J.-D.; MARGUERAT, D. Paul. Une théologie en construction. MBib 51. Fribourg - Paris Montréal: Labor et Fides, 2004, pp. 67-103.

ALETTI, J.-N. New Approaches for Interpreting the Letters of Saint Paul. Collected Essays. Rhetoric, Soteriology, Christology and Ecclesiology. SubBi 43. Roma: GBP, 2012.

AMADOR, J. D. H. "The Unity of 2 Corinthians. A Test Case for a Rediscovered and Re-invented Rhetoric". Neotestamentica 33 (1999), pp. 411-432.

ANDERSON JR, R. D. Glossary of Greek Rhetorical Terms: connected to methods of argumentation, figures and tropes from Anaximenes to Quintilian. Leuven: Peeters, 2000.

für die Einheitlichkeit des 2. Korintherbriefes". In: BIERINGER, R.; LAMBRECHT, J. (Ed.). Studies on 2 Corinthians. BEThL 112. Leuven: Peeters, 1994, pp. 139-140.177-178. 
ARISTOTELIS. Rhétorique. Paris: CUF, 1980.

BARRET, C. K. A Commentary on the Second Epistle to the Corinthians. New York - London: Adam \& Charles Black, 1973.

BAUER, W.; ARNDT, W. F.; GINGRICH, F. W.; DANKER, F. W. A GreekEnglish Lexicon of the New Testament. Chicago - London: University of Chicago Press, $1979^{2}$.

BELLEVILLE, L. L. "Tradition or Creation? Paul's Use of the Exodus 34 Tradition in 2 Corinthians 3,7-18". In: Evans, C. A.; SAnders, J. A. (Ed.). Paul and the Scriptures of Israel. JSTNSS 83. Shefield: Shefield Academic Press, 1993, pp. 165-185.

BEHM, J. “к $\alpha \rho \delta i ́ \alpha ”$ In: KITTEL, G.; FRIEDRICH, G. (Ed.). Theologisches Wörterbuch zum Neuen Testament. IX. Stuttgart: W. Kohlhammer Verlag, 1933, pp. 611-616.

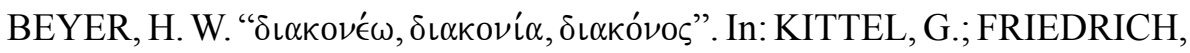
G. (Ed.). Theologisches Wörterbuch zum Neuen Testament. II. Stuttgart: W. Kohlhammer Verlag, 1933, pp 81-93.

BIERINGER, R. "Plädoyer für die Einheitlichkeit des 2. Korintherbriefes". In: Bieringer, R.; Lambrecht, J. Studies on 2 Corinthians. BEThL 112. Leuven: Peeters, 1994, p. 133-179.

BRODEUR, S. N. Il cuore di Paolo è il cuore di Cristo. Studio introduttivo esegetico-teologico delle lettere paoline. I. Theologia 2. Roma: G\&B Press, 2010.

BRUCE, F. F. 1 and 2 Corinthians. NCB. Grand Rapids - London: Eerdmans - Marshall, Morgan \& Scott, 1971.

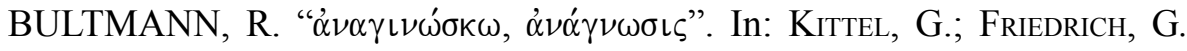
(Ed.). Theologisches Wörterbuch zum Neuen Testament. I. Stuttgart: W. Kohlhammer Verlag, 1933, pp. 347-348.

BULTMANN, R. Zweiter Korintherbrief. Göttingen: KEK Sonderband, 1976.

CARREZ, M. La deuxième épître de Saint Paul aux Corinthiens. CNT VII. Genève: Labor et Fides, 1986.

CHEVALLIER, M.-A. Esprit de Die, paroles d'hommes. Le rôle de l'esprit dans les ministères de la parole selon l'apôtre Paul. Neuchatel: Delachaux and Niestlé, 1966. 
CLARKE, A. D. A Pauline Theology of Church Leadership. LNTS 362. London - New York: T\&T Clark, 2008.

DAVIES, W. D. "Paul and the People of Israel". New Testament Studies 24 (1977-1978), pp. 4-39.

GIVEN, M. D. Paul's True Rhetoric. Ambiguity, Cunning, and Deception in Greece and Rome, Harrisburg: Trinity, 2001.

HARRIS, M. J. The Second Epistle to the Corinthians. A Commentary on the Greek Text. Grand Rapids: Eerdmans, 2005.

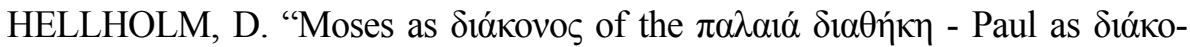

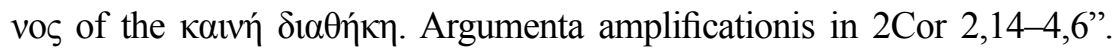
Zeitschrift für die Neutestamentlische Wissenschaft 99 (2008), pp. 247-289.

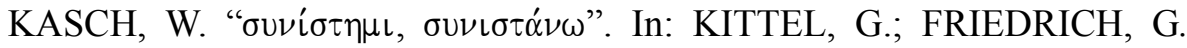
(Ed.). Theologisches Wörterbuch zum Neuen Testament. VII. Stuttgart: W. Kohlhammer Verlag, 1964, pp. 895-896.

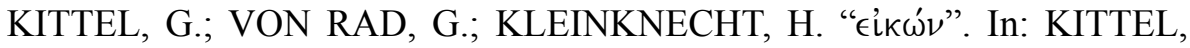
G.; FRIEDRICH, G. (Ed.). Theologisches Wörterbuch zum Neuen Testament. II. Stuttgart: W. Kohlhammer Verlag, 1933, pp. 386-387.

KUSCHNERUS, B. Die Gemeinde als Brief Christi. Die kommunikative Funktion der Metapher bei Paulus von 2Kor 2-5. FRLANT 197. Göttingen: Vandenhoeck \& Ruprecht, 2002.

LAMBRECHT, J. "Structure and Line of Thought in 2Cor 2,14-4,6". Biblica 64 (1983), pp. 344-380.

LAUSBERG, H. Handbuch der Literarischen Rhetorik. Eine Gurndlegung der Literaturwissenschaft. Stuttgart: Franz Steiner Verlag, 1990.

LAUSBERG, H. Elementi di retorica. Bolonha: Il Mulino, 1969.

LONG, F. J. Ancient Rhetoric and Paul's Apology. The Compositional Unity of 2 Corinthians. Cambridge: Cambridge University Press, 2004.

MANZI, F. Seconda Lettera ai Corinzi. Paoline: Milano, 2002.

MARTIN, R. P. 2 Corinthians. WBC 40. Waco: Word, 1986.

MORTARA GARAVELLI, B. Manuale di retórica. Milano: Bompiani, 2002. MURPHY-O'CONNOR, J. Paul the Letter-Writer. Collegeville: Litrugical Press, 1995. 


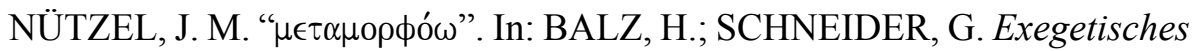
Wörterbuch zum NT. II. Sttutgart - Berlin - Köln, 1992², pp. 1021-1022.

PENNA, R. L'apostolo Paolo: Studi di esegesi e teologia. Cisinello Balsamo: Paoline, 1991.

PHILON D’ALEXANDRIE. De Vita Mosis. II. Paris: Cerf, 1969.

PITTA, A. Disposizione e messaggio della Lettera ai Galati. Analise retoricoletteraria. AnBib 131. Roma: Ed. Pontificio Istituto Biblico, 1992.

PITTA, A. "Così 'inesperto nell'arte retorica'? (cf. 2Cor 11,6). Retorica e messaggio paolino". In: FABRIS, R. (Org.). La parola di Dio cresceva (At.12,24). Fs. C.M. Martini. Rivista Biblica Supplementi 33. Bologna: EDB, 1998, pp. 411-435.

PITTA, A. La seconda lettera ai Corinzi. Roma: Borla, 2006.

PLUMMER, A. Critical and Exegetical Commentary on the Second Epistle to the Corinthians. Edinburgh: T\&T Clark, 1915.

QUINTILIANO, M. F. L’istituzione oratoria. V. Torino: UTET, 1996.

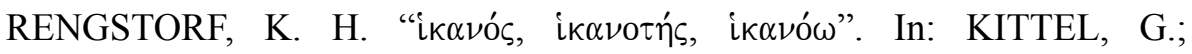
FRIEDRICH, G. (Ed.). Theologisches Wörterbuch zum Neuen Testament. III. Stuttgart: W. Kohlhammer Verlag, 1938, pp. 294-297.

RICHARD, E. "Polemics, Old Testament, and Theology: A Study of II Cor III,1-IV,6”. Revue Biblique 88 (1981), pp. 347-367.

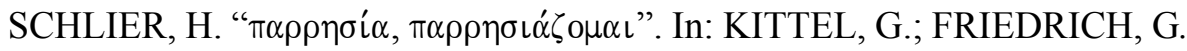
(Ed.). Theologisches Wörterbuch zum Neuen Testament. V. Stuttgart: W. Kohlhammer Verlag, 1954, pp. 869-884.

SCHNEIDER, G. “ $\pi \epsilon \rho \iota \sigma \sigma \in \dot{\omega} \omega ”$. In: BALZ, H.; SCHNEIDER, G. Exegetisches Wörterbuch zum NT. III. Sttutgart - Berlin - Köln, 1992², pp. 180-183.

SCHNEIDER, J. "ó $\mu$ oí $\omega \mu \alpha$ ”. In: KITTEL, G.; FRIEDRICH, G. (Ed.). Theologisches Wörterbuch zum Neuen Testament. V. Stuttgart: W. Kohlhammer Verlag, 1954, pp. 535-554.

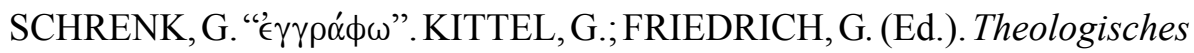
Wörterbuch zum Neuen Testament. I. Stuttgart: W. Kohlhammer Verlag, 1933, pp. 769-770.

SCHÜTZ, J. H. Paul and the Anatomy of Apostolic Authority. New Introduction by Wayne A. Meeks. Louisville - Westminster: John Knox Press, 2007. 
SEGALLA, G. "Struttura letteraria e unità della 2 Corinzi”. Teologia 13 (1988), pp.189-218.

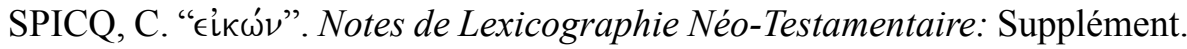
Göttingen: Vandenhoeck \& Ruprecht, 1982.

STEGMAN, T. The Character of Jesus. The Linchpin to Paul's Argument in 2 Corinthians. AnBib 158. Roma: Ed. Pontificio Istituto Biblico, 2005.

THRALL, M. E. A Critical and Exegetical Commentary on The Second Epistle to the Corinthians. I. ICC. London - New York: T\&T Clark, 1994.

TRUMMER, P. “iкavóৎ”. In: BALZ, H.; SCHNEIDER, G. Exegetisches Wörterbuch zum NT. II. Sttutgart - Berlin - Köln, 1992², pp. 452-453.

VANHOYE, A. “L'interprétation d'Ex 34 en 2Cor 3,7-14”. In: LORENZI, L. de. (Org). Paolo. Ministro del Nuovo Testamento. SMBen.Be 9. Roma: Benedictina Editrice, 1987, pp. 159-180.

WITHERINGTON, B. Conflict \& Community in Corinth. A Socio-rhetorical Commentary on 1 and 2 Corinthians. Grand Rapids: Eerdmans 1995, pp. 384-389.

WRIGHT, N. T. The Climax of the Covenant. London - New York: T\&T Clark 1991.

Jean Richard Lopes

Doutor em Teologia Bíblica pela Pontifícia Universidade Gregoriana de Roma Professor do Departamento de Teologia da Pontifícia Universidade Católica de Minas Gerais

Belo Horizonte / MG - Brasil E-mail: jeanrichl@pucminas.br

Recebido em: 23/03/16 Aprovado em: 16/08/16 